\title{
La pintura de historia en España. Tipología y clasificación
}

\author{
jesús Viñuales González
}

Aceptando la denominación específica de Pintura de Historia para el segundo y último tercio del siglo XIX podemos distinguir en la tipologia de esta pintura una serie de coincidencias temáticas y cronológicas que podrian resumirse de la siguiente manera:

Temas retrospectivos y Temas actuales (contemporáneos de los artistas). Dentro de los temas retrospectivos podemos observar cuatro apartados: Temas clásicos; Temas medievales; Temas del Imperio; Temas de la Guerra de la Independencia, este último muy cercano a los pintores de Historia. En los temas que llamamos contemporáneos debemos seguir otro criterio, ya no cronológico, sino ideológico: Temas progresistas y Temas conservadores. Además debemos añadir aquí los que llamariamos Temas periodísticos, o crónicas o apuntes de hechos de armas, batallas, etcétera.

Fuera de la propia pintura de Historia, pero con una gran relación, debemos citar los Temas literarios, que dividimos en varias partes: Retratos de personajes célebres (tanto literarios como políticos y militares); $\mathrm{Te}$ mas históricos relacionados con la literatura, y éstos, a su vez, en dos partes según sean retrospectivos (Entierro de Lope de Vega) o contemporáneos, y por tanto, más documentales (Lectura de Zorrilla en casa del artista); y Temas literarios propiamente dichos (Rinconete, Los amates de Teruel). Igualmente tenemos que incluir en este apartado los Temas religiosos que también son de variada significación temática: Bien tomados de la Biblia o de la vida de los Santos, de carácter hagiográfico; representaciones de parábolas o simbologias de carácter menos histórico y más literario. Por último tendriamos que tratar, fuera del género histórico, pero con evidente relación, los temas costumbristas llamados de "casacón". Esto es, no todos los temas de costumbres, pues está claro que no son 
históricos, aunque a veces nos den noticias históricas acerca de las costumbres, usos y maneras, sino únicamente los llamados de "casacón» por su relación de tratamiento pictórico y estéticu tan similar, en muchas ocasiones, a los de Historia.

$Y$ con esta última frase nos metemos de lleno en el problema que nos ocupa. Esto es, ¿Existe un tipo de tratamiento pictórico de la temática de Historia? ¿Hay algunas caracteristicas generales que se puedan observar de manera continua y uniforme en la pintura de Historia? Para llegar a unas conclusiones que puedan responder a estas preguntas hemos examinado una gran cantidad de cuadros de Historia tratando de ver las características de las distintas tipologias en que la hemos dividido anteriormente. Téngase en cuenta que sólo los conocidisimos pasan del centenar; que Pantorba en su Historia de las Exposiciones de Bellas Artes cita más de quinientas, y que un catálogo completo, por lo que nosotros hemos podido comprobar, superaria los cuatro mil. Solamente la Exposición de 1887 presentó 83 cuadros de historia.

\section{TIPOLOGIA CLASICA}

Dentro de este tipo de pintura de Historia debemos advertir dos cosas de importancia. La primera es la escasez de temas mitológicos (deberíamos clasificarlos dentro de los literarios, pero por su forma de tratamiento encajan mejor aqui), por más que se den algunos ejemplos: “Hércules y Anteo" de Rafael Tejeo; "Dafnis y Cloe" de Bilbao; "Rapto de Europa» de Sotomayor; "Diana en el baño" de Francisco Reygon, etc. Esta escasez se debe al poco interés que existió casi siempre en nuestro país por los temas de Mitologia, y más especialmente en la segunda mitad del siglo XIX. Las causas pueden ser varias, como la influencia de la Iglesia española que pocas veces apoyó el tema mitológico; la ignorancia de nuestro pueblo acerca de estos temas; el carácter universal de la Mitologia reñido con el "chauvinismo» oficial de la pintura histórica; el horror al desnudo (horror observado en la trayectoria general de nuestra pintura) y al que el tema mitológico se presta como ningún otro. Otra causa puede ser la dificultad de extraer (dado el desconocimiento) enseñanzas moralizantes de los asuntos mitológicos. Por último, la fuerte implantación romántica de la pintura de Historia (en cuanto a la anécdota), que no puede ver en los temas mitológicos el suficiente dramatismo para llamar la atención popular.

La segunda advertencia importante consiste en que los temas clásicos vienen impuestos, sin duda, por los regustos neoclásicos a través de 
las Reales Academias, de los Premios y Becas en Roma, de las Exposiciones oficiales que priman esta temática y su tratamiento académico al estilo David.

Con todo, podemos observar dos momentos en la temática clásica: uno, al principio con la "Muerte de Lucrecia», "Muerte de Viriato» de José de Madrazo, etc, y otro, más abundante entre los años 70-80, quizá como reacción al Romanticismo, o por un mejor conocimiento de la historia de aquella época, dado que, para entonces, habian sido publicados una serie de libros y manuales que explicaban los asuntos y la manera de tratarlos verosímil y dignamente. Asi, por citar algunos de este momento, tenemos "Ultimo día de Sagunto" de Domingo Marqués (1842-1920), "Numancia" de Alejo Vera (1834-1923), "La invasión de los bárbaros» de Ulpiano Checa (1860-1916), o el mejor de todos "La muerte de Lucrecia" de Rosales, pintado en 1871.

En toda esta tipología observamos un conocimiento de la historia real, aunque tratada desde un punto de vista anecdótico. Se cuida la anatomía, el dibujo, la composición y en el último momento, también el color. Al principio se da mucha más importancia al dibujo, lo que es lógico al observar la procedencia estilística de esta tipologia, pero con el tiempo se va abriendo camino un tratamiento técnicamente muy bueno del color. Igualmente observamos escasez de paisaje tanto natural como arquitectónico. Las arquitecturas, interiores o exteriores son las imprescindibles para situar la acción en el ambiente determinado y poco más, con algunos erroras de bulto, entrevistos por los artistas, por lo que se evitan en lo posible, aunque las últimas obras cuidan mejor estos detalles de ambientación.

La composición está cuidada al estilo académico, por lo que resultan obras algo frías a pesar de su dramatismo. Se escogen temas precisamente dramáticos para impresionar más fácilmente, pero este dramatismo está conscientemente reprimido o contenido, bien por el academicismo general, por influencias neoclásicas, o bien porque el asunto en si mismo tiene un carácter "heroico" y doctrinal que merecia un respeto y dignidad objetivos. Las obras más tardias, por ejemplo "La invasión de los bárbaros" de Checa, se resienten de exceso anecdótico.

Analicemos someramente una obra de este tipo como ejemplo de lo que venimos exponiendo.

En 1871, dos antes de su muerte, concluye Rosales en Madrid "La muerte de Lucrecia" comenzada en Roma cinco años antes. Es quizá la mejor pintura de Historia de todo el ciclo que nos ocupa en este trabajo, y por lo mismo la mejor de tema clásico. Esto significaria que no deberiamos presentarla como exponente de este género. Pero a pesar de las 
muchas facultades que Rosales exhibe en esta obra, no logra desembarazarse de algunos caracteres que la sitúan hic et nunc.

El tema, tratado antes por Madrazo con menos vis poetica, se refiere al suicidio de Lucrecia ante el deshonor de haber sido violentada por el hijo del rey Tarquino, apodado el Soberbio, lo que según la leyenda determinó, hasta cierto punto, la caida de la monarquia romana.

La verosimilitud está cuidada con detalle. Los hombres visten túnica y toga; Lucrecia estola hasta los pies, de mangas cortas, y manto, recostado en la silla. El calzado de diversos tipos también romano. La silla es de tipo klismos griego utilizado en Roma sin grandes variantes. La columna, de la que se percibe algo más de un tercio, es de tipo compuesto, sin estrías, jaspeada, similar a las de las esquinas exteriores del arco de Tito, por ejemplo. El pebetero es una columna corta con adorno de bucráneo y guirnaldas. Al fondo, en oscuridad, una figura coronada de laurel y con escudo, que pudiera ser una Palas Atenea. Las baldosas de opus cuadratum con pequeños cuadrados en los ángulos. En conjunto es, pues, una escena verosímilmente romana, sin entrar en detalles de cronologia, puesto que se trata de una escena del siglo vi antes de Cristo. Pero esto, en último término, es lo menos importante (para nosotros) ya que algunos criticos de la época se dieron cuenta de «impropiedades".

La obra está bien compuesta, con el grupo central perfecto de dibujo y la impresionante diagonal de Lucrecia moribunda. El brazo y mano izquierdos de Lucrecia son el centro de la obra, que tiene una perspectiva muy corta. En realidad el centro de fuga está situado en la columna, y la habitación se ensancha por este lado izquierdo para situar la escena principal en la parte más ancha. Como además todos los objetos pesan en esta parte, es necesario compensar por la derecha, función que se encomienda al patricio daviniano que sostiene en gesto teatral el arma suicida.

El color es admirable, dominando en general los tonos fríos. El verde de la cortina, los azules de los mantos y los ocres amarillentos luminosos en otras vestimentas se equilibran admirablemente. Los ocres verdosos de las baldosas y los casi negros del fondo contrastan con algunos tonos de color más vivo como el rosa fluorescente de la figura teatralísima de la izquierda y algunos rojos, aqui y allá en las túnicas y sandalias, bien situados.

El conjunto está abocetado, siendo quizá esta característica lo más llamativo e interesante de la obra que le valió a Rosales la incomprensión y crítica del momento. "Modifique un tanto Rosales la excesiva franqueza de su pincel; concluya algo más sus obras, pues el estilo amplio y grandioso a que tiene loable afición está muy lejos de exigir que no se salga de los límites del boceto". Y otro crítico decia que el arte de Rosales queria 
resucitar aquella manera de Velázquez que Palomino llamaba «manera abreviada". (Citados por Pantorba).

La iluminación resalta el sentido fuerte y personal de la mancha y el color. La luz que entra por la derecha ilumina los puntos principales del motivo, especialmente el brazo derecho de Lucrecia modelándolo enteramente.

Es de destacar también que los rostros (ninguno de frente) realistas contrastan con el academicismo y teatralidad de las posturas, asi como con el abocetamiento de toda la obra, realismo que mereció el calificativo de "excesiva franqueza", pero que introduce una tensión por contraste que nos parece de lo mejor logrado, terminando con purismos y estilismos románticos.

A pesar de estas indudables virtudes pictóricas de Rosales, que nos inducen a juzgar esta obra como la mejor de Historia, cae en los defectos generales que hemos señalado reiteradamente: inmenso tamaño, teatralidad académica, verosimilitud forzada, composición fría y estudiada.

\section{TEMAS MEDIEVALES}

Los temas medievales son quizá los más abundantes, pues se prestan a romanticismos sin cuento, a anécdotas curiosas, a ambientaciones misteriosas, a libertad expresiva, a dramatismo más informal. La razón de un peor conocimiento de los hechos históricos (envueltos en leyendas, con mucha influencia de los romances, de las canciones de Gesta y de las tradiciones populares) lleva de la mano a una mala ambientación, desconocimiento de las arquitecturas y cronologia, confusión en vestidos y ropajes, poca verosimilitud en mobiliario y costumbres. Pecan, a su vez, de la poca importancia concedida al paisaje, al menos en un principio, e incluso los interiores se disimulan a base de cortinas o bambalinas acartonadas que demuestran el desconocimiento ambientai. Parecen tramoyas de una compañia teatral barata que piensa que unos detalles arcaizantes pueden ilustar la imagen del pasado. Esto llama la atención tanto más cuanto que los grandes pintores de todas las épocas no han tenido reparos en este orden, y contrasta con el esfuerzo no conseguido, de nuestros pintores de Historia por ajustarse a la verosimilitud.

Pictóricamente hablando, la pintura de temas medievales concede ya mucha más importancia al color que al dibujo, pues trata de impactar por medios cromáticos lo que no puede conseguir por otros medios, aunque 
este esfuerzo no sea consciente ya que pretenden acercarse a la imagen de la realidad, lo que se consigue solamente en la expresividad dramática de las escenas, en la composición más libre, en el desaforado movimiento, en el tremendo colorido y en la elección de temas moralizantes.

En este último sentido existe una evidente intención de deducir moralejas de los hechos expuestos. Así apuntan a la defensa de la autoridad, del poder y orden establecidos; o bien a las consecuencias nefastas de la debilidad de gobierno, o bien (y esto es acorde con la tradición romántica) a la exaltación del triunfo, de la pasión amorosa, de la venganza, ajuste de cuentas, conversiones y muertes repentinas y misteriosas, de indudable efecto patético, moralizador y justiciero, con un sentido de estas cualidades que nos llama la atención, si no supiéramos que todo estaba orquestado por los poderes públicos y oficiales, que pretendian beneficiarse de estos ejemplos, y especialmente de las leyendas sin mucho rigor histórico.

Como apoyatura esclarecedora de lo que venimos diciendo realizamos a continuación un sencillo y breve comentario de una obra concreta muy representativa de esta tipología.

"La campana de Huesca", de Casado del Alisal (1832-1886). Pintado en 1881, se encuentra actualmente en la sala de Justicia del Palacio Municipal de Huesca. Con el título de "La leyenda del rey monje" se presentó en la Exposición Nacional de Bellas Artes del mismo año, adquiriéndola el Estado en 35.000 pts.

Anécdota: Refiere el encuentro de Ramiro II en Monje, de Aragón con los Señores levantiscos en el momento de enseñarles las cabezas de los principales traidores, según leyenda conocida. Ramiro II, (1085?1157). Sucede a su hermano Alfonso I. Casa con inés de Poitiers de quien tiene una hija, Petronila, que casa con Ramón Berenguer IV, en quien abdica Ramiro uniendo Aragón y Cataluña.

Arquitectura y escenificación: Interior de un castillo. Sótano. Piso enlosado. Escalera con sillares no isódomos (para dar impresión de arcaismos constructivo). La entrada del sótano está enmarcada por dos pilastras dóricas con basas semiadosadas, una más ancha que otra, a la izquierda. A la derecha sólo una delgada, después un muro en ángulo en el que se abre una puerta, que da la sensación del muro lateral derecho, y señala de paso la perspectiva. La escalera, que tuerce hacia la izquierda no tiene caja, sino bovedilla, de un tipo raro, de la que se ve el arco que la marca (la mitad, más o menos), de una sola pieza (monolítico), y que se podría denominar deprimido-enviajado. (En el actual Museo Provincial, antigua Universidad y más antiguo Palacio Real oscense, edificado probablemente en el 
siglo XII, bajo Alfonso II, se encuentra una sala llamada "La campana de Huesca". Es muy probable que el pintor conociera esta estancia. Pero no la sigue, sino en el ambiente sobrio y severo de la misma).

Vestuario: En conjunto se acomoda al modo de vestir de las clases altas del románico, especialmente el rey Ramiro, cubierto con manto de tipo bizantino. Sin embargo, el primer personaje de la escalera está vestido a la gótica, y algunos de los demás llevan mantos de tipo romano.

Perspectiva: La perspectiva está centralizada en la pilastra central y más concretamente en la argolla que divide el cuadro en cuatro partes vertical y horizontalmente.

lluminación: La iluminación es teatral. Desde arriba a la izquierda viene la luz, como desde una alta ventana, pero muy pegada al muro, ya que ilumina la pilastra central, la escalera, el grupo de Señores, el brazo y mano de Ramiro, la cabeza y especialmente la barba; más indirectamente las cabezas del suelo, y más fuerte de nuevo las baldosas al pie de la escalera. Deja en oscuridad casi total la bóveda de la escalera, y naturalmente ilumina menos intensamente a los caballeros de segunda fila.

Con esta iluminación se refuerza el dramatismo de la anécdota: las caras de los Señores traidores, las baldosas donde yacen las cabezas, el brazo y barba de Ramiro, el badajo colgante; además de apoyaar la composición que es claramente dual: al lado derecho el grupo de Señores invitados en tropel, las gradas de la escalera y las arquitecturas más poderosas. Al lado izquierdo, Ramiro y su gran perro solos, con la cabeza-badajo y las demás cabezas en el suelo contrapunteados con la oscuridad de la bóveda. Esta dualidad apoya de nuevo la anécdota: por un lado los Señores, por otro Ramiro y su lección de gobierno. Nada de complejidades. La moraleja debe aparecer clara y evidente. El color ayuda en esta labor. Contra el grupo de colores claros y pardos, y las arquitecturas de colores grisáceos y anodinos, aparecen los vestidos de Ramiro, la oscuridad del sotanillo y los rojos de la sangre de las cabezas cortadas. La composición centralizada marca esta dualidad. La argolla, centro del cuadro, es el punto de fuga exacto, con lo que la estancia gana en amplitud, apuntada. No sabemos cómo es de alta la habitación, ni de ancha, pero podemos imaginarla grande, suficiente para más cabezas, como aparecen indicar las más cercanas al espectador. Asi el panorama entrevisto por el espectador, pero medido en toda su dimensión por el grupo de Señores, es más escalofriante. Quizá sea lo único sugerente en serio del cuadro, que, como es lógico, sirve a la intención moralizante. 
De este breve análisis se puede deducir casi todo lo que venimos diciendo: confusión en las arquitecturas y vestuario; composición sencilla dual para no estorbar a la anécdota, sino marcarla más claramente; expresividad dramática, teatralidad romántica, buen dominio de la técnica, del color, de la iluminación y del dibujo. Detalles nimios (como corresponde a un comic popular). Tensión lograda, no por la pintura, sino por la forma anecdótica de la composición -buenos y malos-. Moraleja facilona, a favor de la autoridad y el poder establecido. Pocas sugerencias. Está dicho todo con un lenguaje falto de metáforas, de poesia, en definitiva, de artisticidad.

\section{TEMAS DEL IMPERIO}

A los temas medievales no ceden en número los temas que llamamos del Imperio, esto es, desde los Reyes Católicos hasta Felipe II, más o menos.

En esta tipologia tenemos que observar los siguientes caracteres: En primer lugar existe una clara conciencia de un pasado glorioso venido a menos. Pero esta conciencia de desastre nacional se pretende paliar con un canto excesivo de las glorias imperiales, como si se pretendiese vivir del pasado, de espaldas a la realidad actual. Hasta tal punto que no se reconocen los errores históricos cometidos en aquellos tiempos, y sólo se objetivizan los momentos culmen, que se fijan asi para toda la eternidad o al menos eso se intenta. Es curioso observar a este respecto, que el Estado compra normalmente estas obras y envía las más significativas a centros oficiales de categoria, Palacios o colecciones Reales, Academias de Bellas Artes, Ayuntamientos importantes, dejando las menos representativas para centros de segunda o tercera categoría como colegios nacionales, Ayuntamientos periféricos, Institutos. (Sobre este tema tendremos que realizar un estudio más detallado por si encontramos alguna intención más concreta en cada envío. De momento dejamos constancia de la observación.)

Es cierto que en esta temática se cuida más detalladamente la verosimilitud del ambiente, de los ropajes, mobiliario, retratos, según las crónicas o los manuales de tipologia al uso. Pero no es menos cierto que se desconocen no sólo históricamente, sino incluso a nivel pictórico (composición, dramatismo, expresividad, color, dibujo) las relaciones socio-históricas, socio-políticas e, incluso, religiosas de los temas tratados. Este desconocimiento no podemos asegurar que sea siempre consciente, ya que por más que la pintura oficial esté manejada y manipulada por los poderes 
públicos como hemos asegurado, creemos que a nivel subconsciente, el pintor o el artista responde perfectamente al sentir de una mayoria, gobernantes inluidos, tratando de evadirse de una realidad descorazonadora y desastrosa. (Puesta sobre el tapete, sin embargo, por otros artistas, incluso anteriores como Goya, por los panfletos, ilustraciones y grabados de la época, por la literatura y por los politicos más conscientes.)

Así, pictóricamente hablando, se peca de un esquematismo en la composición, que pone siempre en primer plano de importancia al personaje principal, de quien los demás no son sino meros acompañantes o comparsas, cayendo en una teatralidad de movimiento, de expresividad o de colorido que recuerda de nuevo a la temática clasicista, olvidando aquella tradición romántica de los temas medievales, como no sea en alguna anécdota concreta del tipo de la "Locura de Doña Juana", que da pie fácilmente a los dramatismos más exagerados.

Es interesante observar cómo Pradilla se ajusta al relato de Lafuente poniendo sus dotes de dibujante y colorista al servicio de un dramatismo que por fuerza tenía que resultar popular y que le valió ser considerado un primera línea entre los pintores contemporáneos.

Lo anecdótico del momento elegido en la mayoria de las obras demuestra ese interés por realzar míticamente unas cuantas leyendas o pasajes históricos puntuales, que significa que nuestros pintores están en la misma línea de los novelones o cronicones de donde toman el asunto, a veces con poco rigor histórico, y a rivel artístico, con poco compromiso expositivo. Compárense con otras obras anteriores, como la «Familia de Carlos IV" o los “Fusilamientos» de Goya.

Así pues, se vuelve a una composición academicista como corresponde a unos momentos objetivables de la mayor gloria nacional, o al menos asi se entienden. Con todo, hemos de notar la excelente técnica de las mejores obras y de los mejores artistas, destacando Rosales con el "Testamento de Isabel la Católica»; Gisbert con "Los Comuneros de Castilla»; Pradilla con la "Rendición de Granada", etc.

\section{TEMAS CONTEMPORANEOS}

Todavia dentro de la temática retrospectiva deberiamos incluir los temas de la Guerra de la Independencia. Pero tanto por la cercanía cronológica, como, sobre todo, por el tratamiento ideológico y artístico, comparten caracteristicas de los temas de actualidad o contemporáneos de la pintura de Historia. Por esta razón los citamos aquí, especialmente a los 
mejores, ya que existen obras de la Guerra de la Independencia que se asemejan más a los temas medievales. Pero éstos son los peores artísticamente hablando.

Entre las características más visibles de la temática contemporánea podemos nombrar las siguientes: buen tratamiento del color como es costumbre en toda la pintura de Historia. Pero en éstos hay un mejor dominio de la luz, y no sólo del color. La composición continúa siendo teatral y academicista, pero es más verosímil y realista que en ninguna otra temática, lo que es lógico, pues se trata de temas bien conocidos por el artista. Otro carácter de importancia y que es igualmente lógico, es el dominio del retrato en las composiciones, donde se nota el paso de Goya.

Pero quizá lo más destacable de esta tipología es una división ideológica y social de los temas y de su tratamiento, hasta el punto de que podemos observar dos corrientes o tendencias bien definidas: una que llamaríamos libera! y otra conservadora.

En la tendencia liberal notamos por primera vez en la pintura de Historia un compromiso político, o quizá no debemos exagerar y se trate sólo de una visión social de algunos temas. Este compromiso es, sin duda, burgués, herencia de la Revolución Francesa, de las inquietudes socio-políticas liberales y eco de los mentideros y periódicos de la época. Se recogen escenas dramáticas de actualidad que vienen a demostrar una apertura de las capas liberales que conectan con los problemas de España, aunque hay que advertir que esta conexión es más externa, aparente y formal que verdaderamente profunda e ideológica. En realidad hay que juzgarla como ciertamente progresista, pero sólo desde el punto de vista del liberalismo decimonónico, sin pretender unas motivaciones que únicamente desde nuestros planteamientos actuales estariamos en disposición de descubrir. Incluso este progresismo es muy inferior al que por estas fechas ha prendido en otros países y en otras obras más comprometidas. Pero dentro del panorama evasivo de toda la pintura de Historia española no deja de ser una muestra de importancia de la tendencia liberal.

Por su parte, la tendencia conservadora expone las ideas de orden, tradición, gloria nacional, conectando con la temática que hemos llamado retrospectiva, aunque sólo en la temática, en las consecuencias moralizantes, ya que en el tratamiento estético sigue cánones más parecidos a la tendencia liberal, esto es, realismo, verosimilitud, capacidad y gusto por el retrato, dominio de la luz y el color, por más que la composición es relativamente más academicista y rígida.

Por otra parte, el dramatismo suele estar presente en las escenas de batalias, ejecuciones, en ambas tendericias, tratando de captar partidarios para dichas posiciones ideológicas a través del impacto expresivo, aunque 
no deja de ser una pequeña contradicción que la expresividad en si misma esté normalmente contenida y limitada por la rigidez académica. De otra manera, al menos los temas más liberales y aperturistas no hubieran sido vistos con buenos ojos ni siquiera por aquella parte del público burgués que comulgaba con este débil progresismo sociopolítico.

Como representante más significativo del ala liberal se ha puesto a Gisbert ("Fusilamiento de Torrijos", e incluso "Los Comuneros de Castilla", de carácter retrospectivo, pero inmerso en esa corriente liberal). Casado del Alisal seria el máximo representante del ala conservadora con la «Capitulación de Bailén" o "Santiago en la Batalla de Clavijo", ambas retrospectivas, aunque la de Bailén se consideraba casi contemporánea, o "Las Cortes de Cádiz", obra tratada como oposición a los franceses, no como monumento a la Constitución (?).

"Fusilamiento de Torrijos". Como decimos, Gisbert es el representante más destacado del bando liberal, aunque sólo en los temas, según las opiniones más autorizadas. Famoso desde la Exposición del 60 en que presentó los Comuneros, sus obras de Historia se dedican a ensalzar posturas liberales y un tanto más abiertas y progresistas en su temática. El "Fusilamiento de Torrijos" es quizá su obra principal y mejor acabada de las históricas, ya que posteriormente se dedica a temas de género.

El asunto trata del fusilamiento de Torrijos y sus compañeros el 11 de diciembre de 1831, en Málaga, por orden de Fernando VII, después de abortada su sublevación en el sur de España.

Resaltan en el cuadro los valores y defectos de Gisbert. Defensor de asuntos liberales como indica el tema, severo y razonado en la composición, con dominio de las masas, a las que trata con amplitud, fuerza y elocuencia en el dibujo, verosimilitud en el ambiente y en el retrato de los personajes, realismo documental, meticulosidad en vestidos y composturas, aparecen también sus defectos: entonaciones demasiado frias, falta de color, monótona iluminación, isocefalia compositiva, rigidez en la localización, estratificación en los planos, falta de expresividad y emoción, etc., defectos que contrastan con las obras de su oponente Casado del Alisal que le supera en colorido, iluminación, composición relativamente más abierta, y expresividad.

En conjunto, a pesar de la literalidad temática, esta obra resulta enfadosa, académica, fría, contenida, severa, defectos todos ellos atribuibles en general a la pintura de Historia y que las posiciones liberales no son capaces de superar, quizá por ser exponentes de una ideologia política más que de una apertura a las verdaderas libertades artísticas que un pintor progresista deberia haber asumido. 
Este ejemplo nos introduce en otra clase de tipología, también contemporánea, que hemos denominado periodística. Hay que tener en cuenta que el periódico comienza a ser un medio de comunicación importante. Alli aparecen grabados, ilustraciones, noticias, de gran impacto sobre los lectores, y que generalmente se refieren a hechos contemporáneos. Asi esta influencia llega a los mismos artistas, muchos de los cuales son ilustradores, grabadores, o bien trabajan como corresponsales gráficos.

El más representativo de esta tipologia será Fortuny, becado por la Diputación de Barcelona, con su "Batalla de Tetuán", "La Reina Cristina revistando a las tropas", etc., pero sobre todo con los apuntes de la guerra de Marruecos. El mismo nombre de apuntes nos da idea de cierto cambio en el tratamiento pictórico de los temas. Es cierto que muchos apuntes son directos, tomados de la realidad como si de una cámara fotográfica se tratara. Esta cualidad los hace más nerviosos, expresivos y espontáneos que toda la pintura anterior. Incluso podemos observar una cierta manera impresionista o preimpresionista en su ejecución. Hay que tener en cuenta que esta pintura se dirige al gran público, a tenerle al corriente de las últimas noticias, a conmover a la opinión pública y a los dirigentes, para lo cual es necesario recurrir a una mayor rapidez de ejecución, a una expresividad dramática manifiesta, sin lugar a dudas, a un nerviosismo expositivo muy realista y directo.

A pesar de estos innegables caracteres que, a nuestro juicio, revalorizan estas obras en muchos aspectos, sobre la tradicional y académica pintura de Historia, no dejan de ser deudoras de aquélla en otros muchos, como por ejemplo, en la línea moralizante y de exaltación nacional, la defensa de los valores tradicionales de orden, disciplina y autoridad, apartándose en este sentido de la corriente liberal.

\section{TEMAS COSTUMBRISTAS}

Relacionados con este tipo podemos considerar a los temas de "ocasión" llamados también de "casacón", simbiosis entre la pintura de Historia y la de género, o quizá como consecuencia de la atmósfera de nostalgia y retrospección de las costumbres dieciochescas. En ellos se representan las figuras tocadas con los peluquines y casacas de la época de la llustración. Las primeras obras de este género aparecen en Francia con Meissonier, aunque sus antecedentes puedan ponerse en los maestros menores holandeses del XVII. Fortuny conoció a Meissonier en París, le retrató en "La Vicaría" vestido de militar e impuso el tema en España. 
Esta modalidad parece, en cierta forma, una consecuencia de los cuadros de Historia, aunque en realidad sea su antítesis, pues reacciona contra aquellos lienzos enormes y se oponen a las escenas teatralmente trágicas y enfáticas propias de los asuntos históricos. Lo intrascendente, lo frivolo, lo pomposo, las puntillas y encajes son ideales de la burguesia, enriquecida por el comercio y la industria. El pequeño formato permite (además de acomodarse al presupuesto) el que puedan colgarse en los domicilios particulares, logrando cierto prestigio cultural para sus poseedores.

Asi pues, por un lado se oponen a la pintura de Historia y por otro son deudores de ella. En este sentido y para confirmar nuestra afirmación no es extraño que el mejor pintor de "casacón", Fortuny, sea a la vez el mejor pintor de apuntes y crónicas periodísticas.

\section{TIPOLOGIA LITERARIA Y RELIGIOSA}

En la tipología literaria existe una gran variedad de temas, desde Retratos ("Cervantes pensando en el Quijote", de Mariano de las Rocas) Leyendas ("Los amantes de Teruel», de Muñoz Degrain) Anecdotario con visos históricos ("Entierro de Lope de Vega", de Suárez Llanos) Asuntos literarios propiamente dichos ("Rinconete», de Rodríguez de Guzmán) Testimonios contemporáneos relacionados con las letras ("Lectura de Zorrilla en casa del artista", de Esquivel).

Otro tanto podemos decir de la temática religiosa: Antiguo Testamento ("David y Goliath", de Alenza) Nuevo Testamento ("Jesús en el Tiberiades", de Muñoz Degrain) Vidas de Santos ("Entierro de San Lorenzo", de Alejo Vera) Leyendas relacionadas con la historia ("Santiago en la batalla de Clavijo", de Casado del Alisal) Retratos de Santos y Evangelistas (Rosales, etc.) y hasta Escenas de la Inquisición (Eugenio Lucas).

En conjunto, tanto en una tipología como en otra podemos advertir que la temática está tratada ortodoxamente (en especial la religiosa, por la tradición que ha fijado los temas, desde mucho tiempo atrás), pero en general se tiende a una mayor libertad expositiva, singularmente en la literaria donde la imaginación puede jugar más ampliamente.

Se cuida la verosimilitud, pero con algo más de desenfado que en las escenas propiamente históricas, lo que se traduce en la misma composición, más abierta, y para nuestro gusto, más imaginativa. Con todo, tampoco se atreven aqui demasiado nuestros pintores del siglo pasado, recurriendo a antecedentes con mucha frecuencia. Asi los manierismos y 
barroquismos son evidentes en el tratamiento del santoral, escenas evangélicas, retratos bíblicos, aunque también hacemos notar una corriente prerrafaelista en algunas escenas religiosas. En las más barrocas se tiende a abusar del tenebrismo más que a utilizar contrastes lumínicos. En general el color no es tan rico como en las escenas históricas, pero en las de tendencia prerrafaelista o manierista se hacen intentos saludables en la utilización del color y hasta podemos observar en alguna que otra obra un conocimiento de las técnicas impresionistas.

Es interesante notar que no conocemos ninguna obra de temática religiosa de este período que haya alcanzado verdadera fama o difusión popular, mientras que las escenas relacionadas con la literatura («Entierro de Lope"; "Lectura de Zorrilla", etc.) son muy populares. Tendriamos que exceptuar de este criterio aquéllas de tipo religioso con carga de leyenda histórica como la de "Santiago en Clavijo".

Como ejemplo ilustrativo de estas ideas nos detenemos en una obra de carácter religioso, "Jesús en el Tiberiades", de Muñoz Degrain (1841-1924).

El tema se ajusta a la anécdota: Al amanecer, Jesús, después de una noche sin pescar nada, les dijo que echaran la red y sacaron tantos peces que las barcas se hundian. Ellos dijeros: Es el Maestro. Aparece Jesús en lo alto de una roca (residuo romántico) con túnica blanca que contrasta con la oscuridad de la roca. Los apóstoles en el lago a lo lejos, con las barcas. El sol naciente se refleja en el agua, mientras a lo lejos unas fogatas mañaneras caldean el frío ambiental. Una figura detrás de Jesús, tocada de blanco, se ha percatado de quién es y le rinde adoración.

La composición es muy tradicional y fijada canónicamente. Jesús a la izquierda, muy en primer plano. Unas figuras a su izquierda. Todos en la roca (Recuerda un tanto la "Oración del Huerto", de Mantengna). Los apóstoles y barcas a la derecha, en un plano mucho más pequeño, demasiado pequeño tal vez. El horizonte en neblina y el sol reflejándose simbólicamente en el lago. El sol es el protagonista simbólico de la obra.

El manierismo es evidente en este cuadro de Degrain. Tintoretto tiene una obra "Jesús en el mar de Galilea" de composición muy parecida.

También el simbolismo, no sólo en el sol, sino en la figura blanca de Jesús, simbolismo prerrafaelista, que se deja notar en la meticulosidad del tratamiento, en el amor realista a la naturaleza, amor un poco dulzón, pietista, minucioso, que aquí se equilibra gracias a los elementos técnicos impresionistas como la audacia coloristica y el tipo de pincelada, impresionismo que se hace notorio en el sol y su reflejo que están en la línea del "Soleil levant» de Monet. 
Asi pues, aunque en lo anecdótico sigue la corriente canónica y en lo artístico una mezcla de tratamientos pictóricos, Degrain, que tiene en su haber una obra de historia literaria muy conocida "Los amantes de Teruel», se encuentra aquí más idependiente, más libre en el color e iluminación, en la pincelada, en la ambientación. Las fechas de su vida pueden explicar estas libertades, por lo que se le considera pintor de Historia sólo tangencialmente.

Con esto queremos demostrar lo que deciamos acerca de los caracteres de esta tipología: cánones fijos, manierismo compositivo, libertad técnica, que hacen de esta pintura una avanzadilla dentro de la pintura de Historia.

\section{CONCLUSIONES}

Después de este pequeño panorama sobre la llamada pintura de Historia en España, y de estos sencillos comentarios de algunas obras, podemos llegar a unas conclusiones de interés:

La primera es la gran variedad tipológica de esta pintura. Hemos comprobado que se tratan multitud de temas y desde muchos ángulos de visión, tanto cronológica como anecdóticamente, tanto ideológica como religiosa o culturalmente. De todas maneras creemos que, por número, las obras del Imperio y las medievales son las más abundantes, asi como hemos notado una mayor categoria artística entre las obras dedicadas al Imperio, si exceptuamos los apuntes directos y algunas de tipo literario o religioso, que están más en consonancia con lo que técnica y estéticamente se hace por esas fechas en otros paises. También hemos notado la escasez de asuntos mitológicos, encuadrables dentro de la tipología literaria.

Otra característica estriba en la gran popularidad que han llegado a tener muchas de estas obras históricas, incluso las de mala calidad artística. Las imágenes de tantas glorias nacionales pintadas por estos artistas del siglo pasado han calado en al retina, hasta el punto de que ni el mismo cine ha podido desbancarlas, cuando no ha hecho él mismo uso de estas imágenes, cayendo en verdaderos fallos de rigor. Esto se debe, pensamos, no sólo al apoyo oficial contemporáneo, sino a la política de los Gobiernos posteriores; se puede deber a que casi todos los pintores de alguna talla del siglo XIX se dejaron tentar por este tipo de temática, incluso cuando algunos, como Rosales o Fortuny, estaban más dotados y hubieran dado más de si en otros asuntos y por otros caminos, como lo demuestran en otras obras. Se puede deber también a que, con posteriori- 
dad, los pintores españoles de fama mundial (Picasso, Dali, Miró, Gris, etcétera) o no han tocado el tema histórico, o lo han hecho con tratamientos tan distintos, técnica y estéticamente ("Guernica", por ejemplo), que han dejado intactas las imágenes creadas por aquellos pintores históricos. Incluso artistas que se han dedicado a desmitificar (Equipo Crónica, por ejemplo) no han entrado en la misma temática, seguramente por parecerles que no merecia la pena dedicarse a pintores y obras que valoraban negativamente.

Otra de las características de esta pintura es que las técnicas y las formas de tratamiento artístico suelen ser distintas para los distintos temas, dentro de un conjunto en el que predomina el academicismo.

Suele ser o pretende ser rigurosa en la verosimilitud, hasta donde se sabia en este tiempo, pues hemos observado la presencia y publicación de manuales que cuidaban estos detalles hasta el máximo, por más que, como hemos advertido, la ignorancia o la confusión histórica se dejen notar claramente en muchas composiciones, sobre todo a nivel de arquitecturas, mobiliario, ambientación, etc.

Con todo, el deseo y el interés por ajustarse a las opiniones de los eruditos ha llevado a esta pintura a caer en un academicismo a ultranza que se nota en los cánones fijos, en las proporciones y situación de los personajes, en la comedida y fría composición, en el abuso del color para paliar la falta de expresividad, en el dramatismo contenido, a pesar de la temática, etc. de lo que resultan unas obras de grandes dimensiones que estéticamente pecan por lo general de falta de vis poetica, esto es, sejeman cromos más que una verdadera obra de arte.

Debemos hacer una aclaración. Cuando decimos que estos pintores conocen la técnica, nos referimos precisamente a eso, a la maestría en el hacer, al dominio de los secretos del dibujo y del color, al conocimiento de las reglas de la composición académica, es decir, a todos los oficios del maestro de pintura. De aquí la acusación de que no hayan sabido o querido trascender el mero oficio o no lo hayan puesto al servicio de una causa más interesante artísticamente hablando. $Y$ cuando decimos falta de expresividad no hacemos referencia a gestos violentos, a movimientos convulsivos, a misteriosas situaciones que ciertamente aparecen en muchas obras, sino a la garra expositiva, a la vis poetica, a la fuerza expresiva, a la sugerencia universal que debe contener toda obra de arte.

En otro sentido esta pintura resulta apriorística, parcial, oficialista, de espaldas a la realidad política y social de su tiempo, poco o nada comprometida, de gran realismo anecdótico, pero no social, de buena técnica como hemos dicho, pero tradicional y sin apertura a nuevas formas. 
Estas graves deficiencias de la pintura de Historia vienen, a nuestro parecer, de las teorias históricas del siglo pasado que dominaron en los ambientes cultos, singularmente las de Ranke y Herder.

Por un lado el nacionalismo de Herder, tan bien acogido por el Romanticismo, su teoria de las especializaciones sucesivas, según la cual sólo la raza establecida en Europa Occidental es histórica, e incluso dentro de ésta, el diverso comportamiento de unos hombres a otros, de unas naciones y otras señala las diferencias, tendría que influir en las mentes de nuestros artistas que se dedican a ensalzar aquellos comportamientos puntuales de nuestra historia que demuestran la superioridad de una raza y de una nación, o al menos la singularidad, como quiere cualquier nacionalismo.

Por otro lado, las tesis positivistas, especialmente las de Ranke con sus ideas de objetividad llevadas al extremo de que cada uno de los hechos históricos debe ser considerado y comprendido aisladamente sin conexión y dependencia relacional. ¿No son los cuadros de historia de esta época, momentos sueltos, aislados de gloria nacional, episodios que no quieren ser relacionados ni causados por nada que no sea la singularidad de una nación? Así nos parecen ahora piezas de museo sin ninguna o poca relación con la realidad de España, y por esto mismo, subjetivas, esto es, todo lo contrario de aquella objetividad buscada con tanto afán y tan defectuosamente, que se convierte en algo abstracto, independiente, más similar a unos dogmas trascendentes que a una pintura de hechos históricos que son siempre dependientes de una compleja red de relaciones.

De todo estos resulta, como hemos indicado, una influencia en la imagen de la Historia de España con todos los errores de situaciones, acontecimientos que aún perdura. Como muestra exagerada citamos dos ejemplos: uno literario, otro plástico de dicha influencia. En el libro Glorias imperiales, tomo II, de Luis Ortiz Muñoz, Madrid, 1940 en la página 36 se puede leer: “Desde aquel Alcazar, el Emperador gobernó muchos años la vida de Europa y de América. Alli se concertaron las más grandes epopeyas y hazañas. Alli vinieron a pedir novia los Soberanos del mundo. Desde alli fue imparcial la dinastia de los Habsburgo, que entronizaba Reyes y Príncipes en las incipientes naciones modernas. El soberbio monumento estaba predestinado a ser inmortal. Porque años después, en nuestros mismos días, habria de revivir toda su pasada gloria y ser la fortaleza invencible del momento imperial contemporáneo". Y en la misma obra, pág. 25, una ilustración de Cobos sobre la "Muerte de Isabel la Católica".

Esta postura anticrítica y antiobjetiva de nuestra Historia ha supuesto un grave retroceso en el análisis de la realidad de nuestros tiempos histó- 
ricos, y lo que es peor, un retroceso en el análisis de su tiempo, ya que el prisma analítico es invariablemente único (moralina, defensa de valores conservadores), salvo en algunas obras de la tendencia liberal que introducen un cierto aire de apertura, aunque sin comprometerse demasiado.

De todos modos, y subconscientemente, no podian los pintores de historia dejarnos un análisis mejor de la realidad de su época, ya que a través de su obra podemos juzgar cómo era y se vivia la segunda mitad del siglo pasado, en general: de espaldas a la realidad, con evasiones oficiales y populares de los graves acontecimientos políticos y sociales, con un desencanto interior que obliga a buscar compensaciones, con ningún deseo de hacer frente a la situación y buscar soluciones auténticas refugiándose en el orgullo de los tiempos pasados, con una conciencia clara del desastre y liquidación precisamente de aquellos tiempos, con una falta de visión política y social asombrosa, con una autarquía cultural que impide asomarse a otras experiencias. Los pintores de historia viajan bastante, pero normalmente se limitan a ambientes oficiales y académicos.

En definitiva, la pintura de Historia, aun examinada someramente, como hemos hecho y posiblemente a pesar suyo, tiene el mérito de dejarnos un testimonio plástico y contundente del pensamiento que dominaba en los círculos científicos y culturales (nacionalismos, patrioterismos, positivismos, etc.) y también de la forma en que fue asumida la realidad por parte de los españoles, tanto a nivel popular como oficialmente. Por esto pensamos que este tipo de pintura continúa siendo un filón importante para el conocimiento de aquel tiempo e, incluso, para el entendimiento de muchos acontecimientos posteriores que hunden sus raices ideológicas alli y que en casos, llegan hasta nuestros dias. 

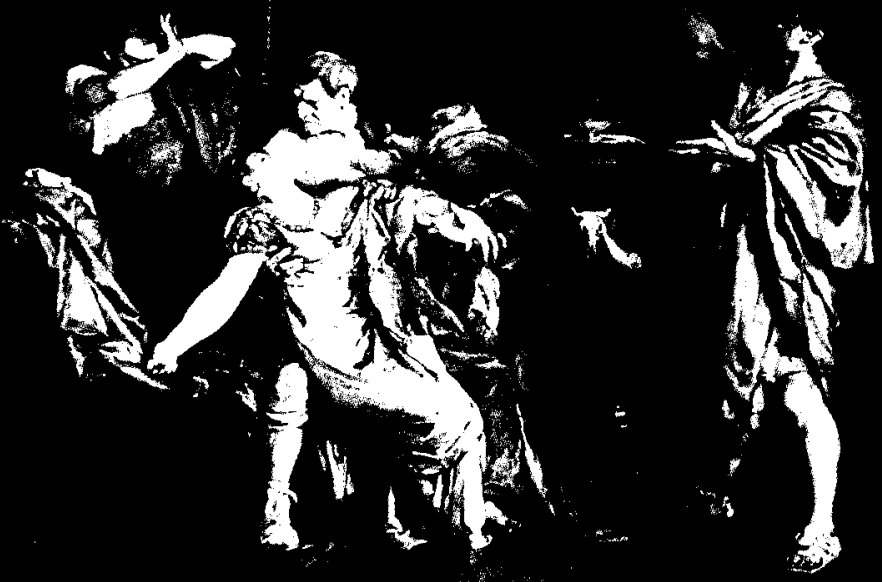

Fig. 1. Rosales. La muerte de Lucrecia.

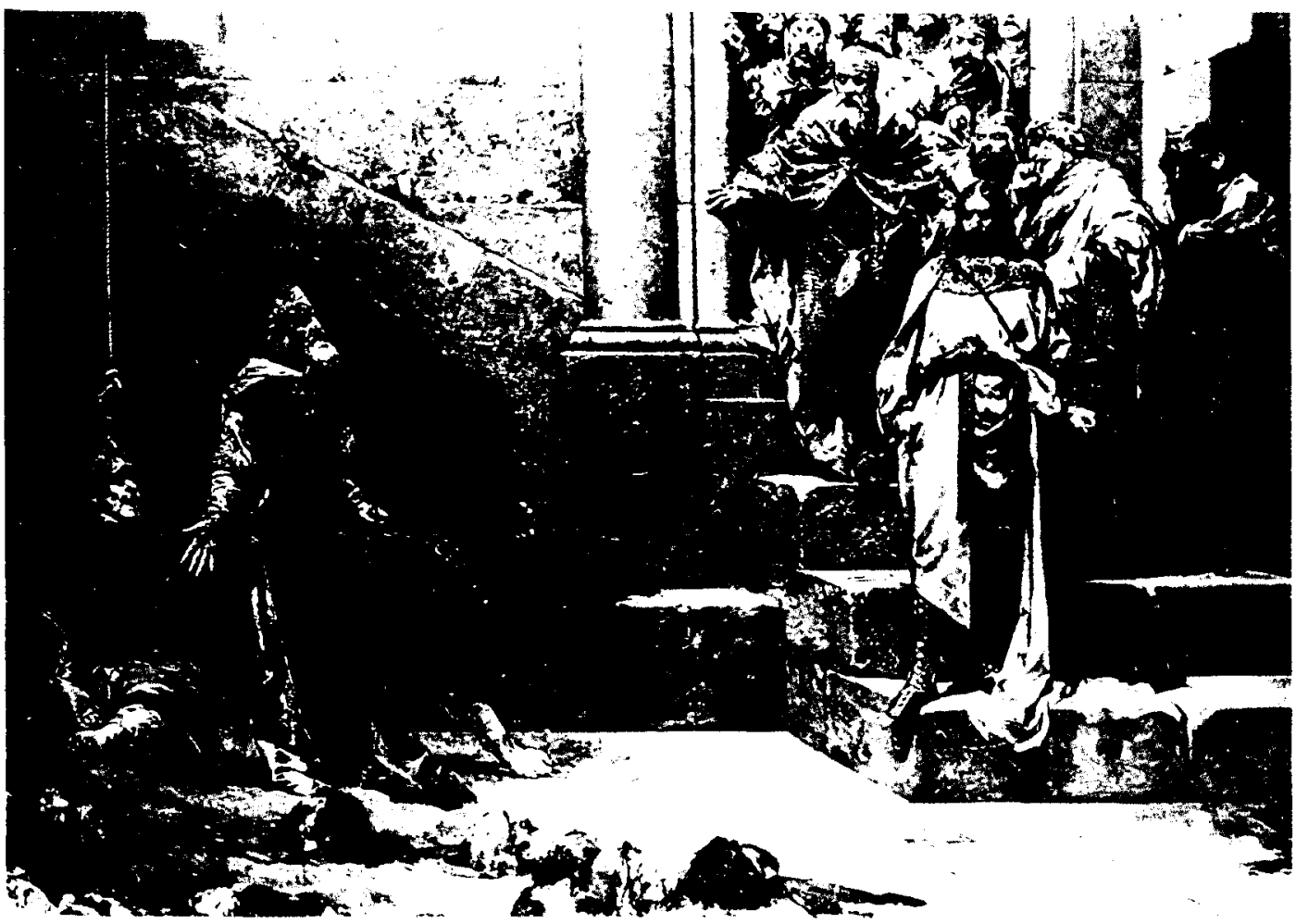

Fig. 2. Casado del Alisal. La campana de Huesca. 


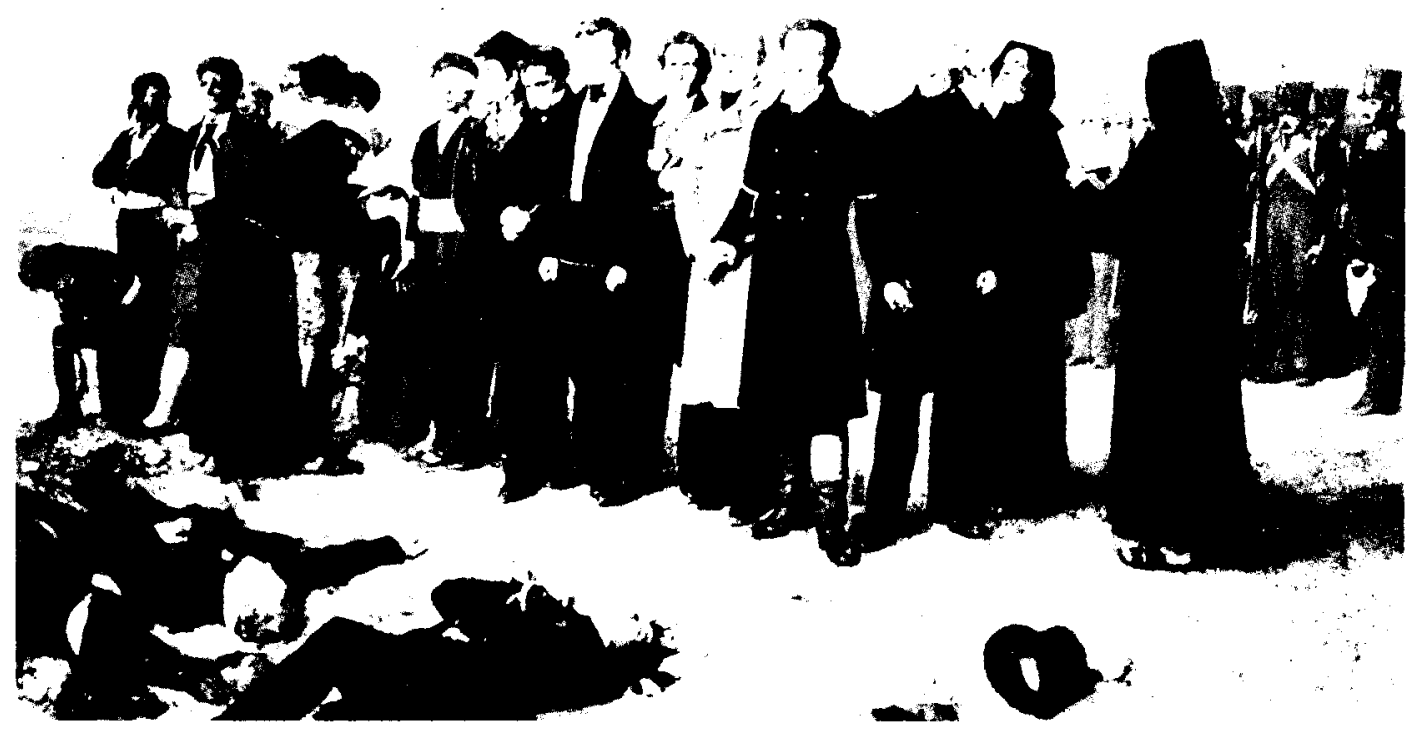

Fig. 3. Gisbert. Fusilamiento de Torrijos y sus compañeros.
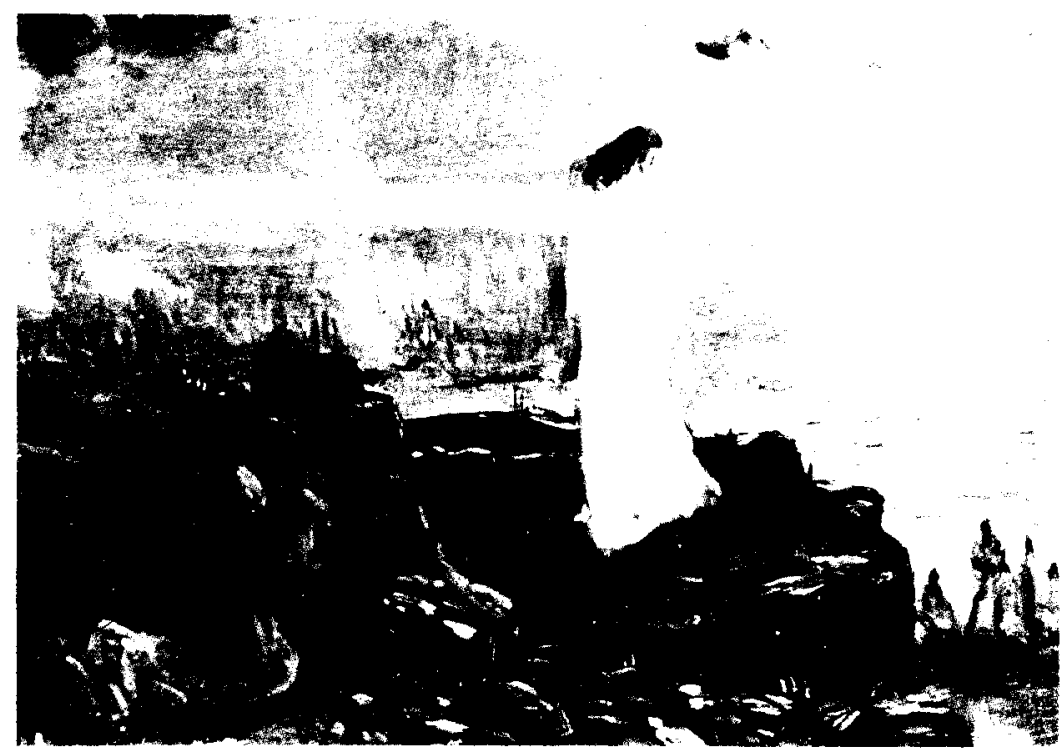

Fig. 4. Muñoz Degraın. Jesus en el Tiberiades. 